\title{
Timing the oxygenation of the deep oceans using $\delta^{238} \mathbf{U}$
}

\author{
J. B. RODNEY ${ }^{1 *}$, D. STUBBS ${ }^{1}$, C. J. LISSENBERG ${ }^{2}$, M.B. \\ ANDERSEN $^{2}$, T. ELLIOTT ${ }^{1}$ \\ ${ }^{1}$ Bristol Isotope Group, School of Earth Sciences, University \\ of Bristol, Bristol BS8 1RJ, UK. (*Correspondence: \\ joel.rodney@bristol.ac.uk) \\ ${ }^{2}$ School of Earth \& Oceanc Sciences, Cardiff University, \\ Cardiff CF10 3AT, UK
}

Oxygenation of the deep oceans represented a major change in the surface environment but was also a key control in the oxidation of the mantle via subduction. Knowing when this occurred is thus critical to understanding both aspects of Earth evolution. Recent estimates suggest deep ocean oxygenation did not occur until the late Palaeozoic [1], but additional constraints on this timing would be valuable.

Recently, the documentation of natural isotopic variations in uranium (U) has been applied to better understand its redox sensitive geochemical cycle [e.g. 2]. It is possible to exploit these isotopic variations to examine when the deep oceans became oxygenated.

In modern oxic oceans, $\mathrm{U}^{6+}$ can be reduced to $\mathrm{U}^{4+}$ during incorporation into the oceanic crust during its alteration. This imparts an isotopic fractionation that gives modern altered oceanic crust an isotopically distinct ${ }^{238} \mathrm{U} /{ }^{235} \mathrm{U}$ ratio [2]. For this diagnostic isotopic signal to be generated in the oceanic crust, a strong redox gradient between (oxygenated) deep oceans and oceanic crust is needed. Therefore, determining when this isotopic signal was first generated in the altered oceanic crust allows us to infer when the deep oceans became oxygenated.

Here we will present $\delta^{238} U$ (the parts per thousand difference in ${ }^{238} U /{ }^{235} U$ relative to CRM 145) data for ophiolite pillow basalts and sheeted dykes, spanning the Phanerozoic, to constrain the time range over which the deep oceans have been oxygenated. Our preliminary results suggest limited U isotope fractionation in $480 \mathrm{Ma}$ samples, consistent with reduced deep oceans at this time, in agreement with other redox sensitive proxies [1]. Further work on a wider range of ophiolites will be able to refine this time window.

[1] Stolper \& Keller., (2018) Nature. 553, 323-327. [2] Andersen et al., (2015) Nature. 517, 356-359. 